\title{
Gambaran Kejadian dan Tingkat Kecemasan pada Lanjut Usia
}

\author{
Rindayati ${ }^{1}$, Abd. Nasir ${ }^{2}$, Yuni Astriani ${ }^{3}$ \\ 1,2Prodi D3 Keperawatan Fakultas Vokasi Universitas Airlangga, Surabaya, Indonesia \\ ${ }^{3}$ Rumah Sakit Nyai Ageng Pinatih Gresik \\ rindayati-2019@fkp.unair.ac.id'1, abdoel.nasir@vokasi.unair.ac.id², yuniastriani159@gmail.com³
}

Diajukan 31 Januari 2019 Diperbaiki 22 April 2020 Diterima 11 Mei 2020

\section{ABSTRAK}

Latar Belakang: Lanjut usia merupakan tahap terakhir dari proses pertumbuhan seorang manusia. Pada lanjut usia terjadi perubahan baik secara biologis, emosional maupun psikososial yang berpotensi memunculkan masalah kesehatan, dimana salah satunya adalah terjadinya kecemasan.

Tujuan: Tujuan dari penelitian ini adalah untuk mengetahui gambaran kejadian dan tingkat kecemasan pada lanjut usia.

Metode: Desain pada penelitian ini adalah deskriptif, dengan populasi lanjut usia sesuai dengan kriteria inklusi dan kegiatan Posyandu dilakukan di Desa Wedani Cerme Gresik, pada 23 Juni 2018 dimana lanjut usia turut mengunjungi. Teknik pengambilan sampel menggunakan total sampling dengan sampel sebanyak 41 responden. Pengumpulan data menggunakan kuesioner Hamilton Anxiety Rating Scale. Etical Approvel oleh Fakultas Keperawatan Universitas Airlangga nomor 771-KEPK, 23 April 2018.

Hasil: Hasil penelitian ini 56\% tidak terjadi kecemasan dan $44 \%$ terjadi kecemasan, dimana seluruhnya dengan tingkat kecemasan ringan.

Kesimpulan: Kemunduran yang terjadi pada lanjut usia dapat mengakibatkan kecemasan pada sebagian orang, dan tidak pada sebagian yang lain. Perhatian, rasa aman dan penyediaan fasilitas kesehatan sangat penting diberikan kepada lanjut usia untuk mencegah terjadinya kecemasan dan solusi bagi yang mengalami kecemasan.

Kata Kunci: kejadian dan tingkat kecemasan; lanjut usia

\section{ABSTRACT}

Background: Elderly is the last stage of a human/s growth process. Changes in the elderly at this occur both biologically, emotionally and psychosocially have the potential to cause health problems, where one of them is the occurrence of anxiety.

Objective: This purpose of this study is to determine the description of the incidedence and level of anxiety in the elderly.

Methods: The design in this study was discriptive, with the elderly population according to inclusion criteria and at the time the posyandu was conducted inthe village of Wedani Gresik. The sampling technique used total sampling with a sample of 41 repondents. Data collection using the Hamilton Anxiety Rating Scale (HARS) questionnire, processed by editing, coding, scoring, tabulating and analyzed descriptive with precentages. Ethical Approvel by the Faculty of Nursing Airlangga University number 771-KEPK, April 2018.

Results: The results this study are that most of the elderly as many as 23 repondents (56\%) did not have anxiety and almost half, as many as 18 respondents (44\%) had anxiety, where all with mild anxiety levels. Conclusion: Setbacks that occur in the elderly can cause anxiety in some people, and not in others. Education, attention, security and the provision of health fasilities are very important given to the elderly yo prevent anxiety and solution those who experience anxiety.

Keywords: incident and anxiety leve; advanced age 
PENDAHULUAN

Penuaan adalah terjadinya akumulasi perubahan pada manusia dari waktu ke waktu yang meliputi perubahan biologis, psikologis dan sosial yang berkorelasi terhadap penurunan daya tahan tubuh dan terjadinya penyakit (Kar, 2019). Kemampuan adaptasi yang kurang dalam menghadapi perubahan, dapat menyebabkan masalah psikososial, salah satunya adalah ansietas (Maramis dan Maramis, 2009). Kecemasan sendiri dapat berpotensi buruk terhadap fisik, psikologis, maupun perilaku pada lanjut usia. Namun, gambaran terjadinya kecemasan dan tingkatannya belum diketahui dengan jelas sampai saat ini.

Peningkatan usia harapan hidup yang luar biasa berdampak pada peningkatan jumlah populasi tua yang bertambah pesat. Jumlah orang berusia 65 atau lebih tua diproyeksikan akan meningkat dari 524 juta pada tahun 2010 menjadi hampir 1,5 miliar pada tahun 2050, dengan peningkatan terbesar berada di negaranegara berkembang (World Health Organization, 2011). Riset Welzel F.D et all., (2019) menyatakan individu usia diatas 82 tahun yang menderita gejala kecemasan sebanyak 14,5\% (Welzel et al., 2019).

Proyeksi lanjut usia di seluruh dunia pada tahun 2013 diasumsikan sebesar 7,2\%, tahun 2050 sebesar 9,6\%, dan pada tahun 2100 sebesar 10,9\% dari seluruh penduduk dunia (Kementerian Kesehatan RI, 2014). Berdasarkan Data Sensus Ekonomi Nasional Badan Pusat Statistik (BPS) 2017, jumlah lansia di Indonesia 23,4 juta jiwa (8,97\%). Tahun 2015 diperkirakan mencapai 33,7 juta $(11,8 \%)$ dan 2035 sebanyak 48,2 juta dari jumlah penduduk (15,8\%) (Profil Kesehatan Indonesia, 2012).

Lanjut usia di Jawa Timur pada tahun 2016 sebesar 4.602 .390 juta $(11,80 \%)$, dengan perincian lanjut usia perempuan 2.488.285 juta (12,59\%) dan laki-laki $2.114 .106(10,98 \%)$, yang berarti bahwa jumlah lanjut usia perempuan lebih banyak dari laki-laki. Profil Jawa Timur tahun 2016 membagi jumlah lanjut usia berdasarkan kelompok umur yaitu jumlah lanjut usia muda (60-69 tahun) sebesar 7,19\%, lanjut usia menengah (70-79 tahun) sebesar 3,46\%, dan lanjut usia tua (80 tahun ke atas) sebesar 1,14\% (Profil Jatim, 2017). Kondisi di Kabupaten Gresik, lanjut usia laki-laki sebanyak 7,62\% dan lanjut usia perempuan 9,26\%. Menurut Videbeck (2011), lanjut usia yang mengalami ansietas sebanyak $50 \%$ dan sebagian besar berada di negara berkembang (Videbeck, 2011).

Proses menua merupakan proses yang terus-menerus terjadi penurunan kemampuan jaringan secara alamiah dan tidak mungkin dapat kembali seperti semula, bahkan semakin bertambah tingkat usia jumah penurunan jaringan semakin banyak (Constantinides, 1994). Proses penuaan secara degeneratif akan berdampak pada perubahan fisik, kognitif, perasaaan, sosial dan seksual (Azizah, 2011). Masalah pada perasaaan diantaranya adalah ansietas atau kecemasan. Kecemasan adalah kondisi emosi yang ditandai dengan perasaan tegang, pikiran cemas dan perubahan fisik seperti peningkatan tekanan darah, gemetar, nyeri kepala dan lain-lain (American Psychological Association, 2019).

Gejala kecemasan secara umum pada lanjut usia yaitu perubahan pada tingkah laku, gelisah, kemampuan konsentrasi berkurang, kemampuan menyimpan informasi berkurang, dan keluan pada badan seperti kedinginan, telapak tangan lembab dan lain-lain (Maryam, 2008). Dampak kecemasan pada lansia dapat menimbulkan masalah seperti Irritable Bowel Syndrom (IBS) atau sakit kepala migraine (Harvard Medical School, 2018).

Lanjut usia memerlukan perawatan untuk mencegah terjadinya masalahmasalah yang terjadi terkait dengan kesehatan jiwa, tetapi pemberian motivasi untuk membuat lansia bahagia di akhir 
kehidupannya sangat perlu untuk dilakukan (Maryam, 2008). Mengatasi kecemasan yang terjadi pada lanjut usia dapat pula dilakukan dengan relaksasi dan distraksi (Keliat, 2013). Dari pemaparan diatas, maka dirumuskan masalah penelitian "Bagaimanakah gambaran kejadian dan tingkat kecemasan pada lanjut usia?".

Penelitian ini bertujuan untuk mengetahui gambaran kejadian dan tingkat kecemasan pada lanjut usia di posyandu Lansia Cerme Kabupaten Gresik. Adapun manfaat penelitian adalah untuk meningkatkan mutu dalam memberikan asuhan keperawatan gerontik khususnya masalah psikososialkecemasan.

\section{METODE}

Jenis penelitian ini termasuk penelitian kuantitatif dengan pendekatannya menggunakan desain deskriptif, yaitu salah satu penelitian yang tujuannya untuk menyajikan gambaran secara lengkap mengenai kondisi sosial atau untuk melakukan eksplorasi dan klarifikasi mengenai suatu kenyataan yang ada di masyarakat, dengan cara mendeskripsikan valiabel-variabel penelitian (Nursalam, 2014). Penelitian ini mendeskripsikan kejadian dan tingkat kecemasan pada lanjut usia dengan batasan usia (60-90 tahun). Penelitian dilakukan pada bulan Februari - Juni 2018, adapun lokasi penelitian adalah di Posyandu Lansia Cerme Kabupaten Gresik.

Populasi didefinisikan sebagai suatu subjek penelitian dengan kriteria yang sudah ditetapkan (Polit \& Hungler, 1999). Populasi dari penelitian ini meliputi lanjut usia yang diikutsertakan pada kegiatan posyandu lansia Cerme Kabupaten Gresik dengan jumlah 41 responden. Sampel adalah bagian dari populasi yang dianggap dapat mewakili dari keseluruhan obyek yang diteliti (Setiadi, 2013). Lanjut usia yang berumur 60-90 tahun sebanyak 41 responden yang hadir pada kegiatan posyandu diikutkan sebagai sampel pada penelitian ini. Sampling didefinisikan sebagai kegiatan menyeleksi peserta penelitian yang dijadikan sampel untuk mewakili populasi (Setiadi, 2013). Teknik total sampling dilakukan pada penelitian ini, yaitu dengan cara seluruh jumlah populasi dijadikan sampel karena jumlah populasi penelitian jumlahnya kurang dari 100 (Sugiyono, 2006).

Pengumpulan data adalah proses pengumpulan dan pegukuran informasi yang dilakukan secara sistematis, digunakan untuk menjawab pertanyan penelitian. Pengumpulan data dilakukan dengan langkah-langkah sesuai rancangan penelitian dan teknik instrumen yang digunakan (Gray et al., 2016). Pengumpulan data penelitian ini diawali dengan mengurus surat ijin penelitian, dilanjut mengurus surat etik penelitian, dan surat ijin pengambilan data. Setelah mendapat persetujuan dari masingmasing pihak, peneliti melaksanakan penelitian dengan tahapan yaitu pendekatan kepada lansia untuk mendapatkan persetujuan menjadi responden, menandatangani informed consent, pembagian kuesioner, dan pengumpulan kembali kuesioner pada hari itu juga. Peneliti melakukan pengecekan dan penilaian pada jawaban kuesioner yang telah diisi oleh responden. Instrumen penelitian adalah alat bantu dalam penelitian yang penggunaannya untuk mengumpulkan data yang valid, reliable, dan aktual (Nursalam, 2014). Instrumen penelitian ini menggunakan Hamilton Anxiety Rating Scale (HARS), dan bersifat tertutup.

Tahap-tahap pengolahan data penelitian ini sebagai berikut, yaitu 1) Editing yaitu kegiatan ulang dilakukan untuk mengecek isi kuesioner, agar jawaban yang diperoleh dari responden lengkap. 2) Coding merupakan kegiatan diklasifikasinya jawaban responden 
kedalam kategori dengan cara diberi kode. Pengelolaan data dilakukan dengan cara mengumpulkan data dan memberikan kode-kode yang sesuai dengan kategori yang telah direncanakan dengan diberikan kode berupa angka. 3) Skoring dilakukan peneliti, kemudian memberikan nilai dengan kategori, dan skor. Penilaian hasil pengumpulan data dari lembar kuesioner diberi skor berupa kode angka. Kegiatan selanjutnya adalah melakukan skoring dengan: (1) Skor setiap item, skor $0=$ tidak ada gejala sama sekali, skor 1 = satu gejala dari pilihan yang ada, skor 2 = separuh dari gejala yang ada, skor $3=$ lebih dari separuh gejala yang ada dan skor 4 = semua gejala ada. (2) Total skor, kurang dari 14 = tidak ada kecemasan, 14$20=$ kecemasan ringan, $21-27=$ kecemasan sedang, 28-41 = kecemasan berat dan 42-56 = panik. 4) Tabulating yaitu kegiatan untuk memasukkan data ke dalam tabel, kemudian menghitung banyaknya frekuensi untuk tiap data yang terkumpul baik data umum maupun data khusus. 5) Persentase. Setelah data dikelompokkan dalam tabel distribusi frekuensi, kemudian dilakukan perhitungan dengan menggunakan rumus untuk memperoleh persentase.

Penelitian ini melakukan analisa data dengan pembagian data umum dan data khusus yaitu tentang kecemasan dengan menggunakan analisa deskriptif. Analisa deskriptif ini dilakukan dengan maksud agar diperolehnya gambaran kejadian dan tingkat kecemasan pada lanjut usia (60-90 tahun). Etika penelitian menggunakan format yang diisi oleh responden berupa lembar persetujuan (informed consent), menjaga kerahasiaan (confidentiality), serta tanpa nama (anonimity).

\section{HASIL DAN PEMBAHASAN}

Pelaksanaan penelitian ini bertempat di Posyandu Lansia Cerme Kabupaten Gresik. Jumlah lansia yang mengikuti kegiatan posyandu sebanyak 57 orang, sedangkan yang sesuai dengan kriteria inklusi sebanyak 41 orang, terdiri dari pra lansia 6 orang, sebagaian besar responden berusia 60-70 tahun sebanyak 21 responden (51\%), hampir setengah responden berusia 71-80 tahun berjumlah 11 responden (27\%) dan sebagian kecil responden berusia 81-90 tahun berjumlah 9 responden $(22 \%)$.

Tabel 1. Karakteristik responden berdasar usia, jenis kelamin, dan tingkat pendidikan serta distribusi responden berdasarkan kejadian dan tingkat kecemasan

\begin{tabular}{|c|c|c|c|}
\hline \multirow{2}{*}{\multicolumn{2}{|c|}{ No Uraian }} & \multicolumn{2}{|c|}{ Responden } \\
\hline & & Jumlah & Persentase \\
\hline \multicolumn{4}{|c|}{ Usia } \\
\hline & $60-70$ tahun & 21 & 51 \\
\hline 2 & 71-80 tahun & 11 & 27 \\
\hline & $81-90$ tahun & 9 & 21 \\
\hline \multicolumn{4}{|c|}{ Jenis kelamin } \\
\hline & Laki-laki & 14 & 34 \\
\hline & Perempuan & 27 & 66 \\
\hline \multicolumn{4}{|c|}{ Pendidikan } \\
\hline & Tidak sekolah & 13 & 32 \\
\hline 2 & SD & 12 & 29 \\
\hline & SLTP & 6 & 15 \\
\hline 4 & SLTA & 8 & 19 \\
\hline 5 & PT & 2 & 5 \\
\hline \multicolumn{4}{|c|}{ Kejadian kecemasan } \\
\hline 1 & Tidak cemas & 23 & 56 \\
\hline & Cemas ringan & 18 & 44 \\
\hline \multicolumn{4}{|c|}{ Tingkat kecemasan } \\
\hline 1 & Tidak terjadi & 23 & 56 \\
\hline 2 & Ringan & 18 & 34 \\
\hline 3 & Sedang & 0 & 0 \\
\hline & Berat & 0 & 0 \\
\hline
\end{tabular}

Berdasarkan tabel 1 pada kelompok usia dapat dilihat bahwa sebagian besar responden berusia 60-70 tahun, sebanyak 21 responden $(51 \%)$, dan sebagian kecil berusia 81-90 tahun sebesar 9 responden (22\%). Usia 60 tahun adalah awal menjalani masa lansia, saat ini lansia harus menghadapi perubahan-perubahan seperti kulit keriput, mata mulai kabur, keseimbangan tubuh berkurang, penyakit degeneratif mulai banyak menyerang. Kondisi demikian merupakan stresor yang harus diadaptasi oleh lansia dan 
apabila adaptasi kurang baik maka dapat menyebabkam kecemasan (Maramis dan Maramis, 2009). Menurut petugas program lansia puskesmas Cerme yang diperoleh melalui wawancara, beberapa tahun terakhir lansia yang berobat ke poli lansia maupun ke posyandu lansia dari hasil pengkajian dengan Kartu Menuju Sehat (KMS) lansia, didapatkan banyak lansia mengalami kecemasan

Berdasarkan tabel 1 pada kelompok jenis kelamin menunjukkan bahwa sebagian besar responden memiliki jenis kelamin perempuan sebesar 27 responden (66\%) dan hampir setengah responden berjenis kelamin laki-laki sebesar 14 responden (34\%). Penelitian ini menemukan bahwa jenis kelamin dapat mempengaruhi terjadinya kecemasan pada lansia dimana wanita dua kali lebih banyak terjadi kecemasan pada lansia. Hasil penelitian ini diafirmasi oleh hasil penelitian sebelumnya oleh Remes, $\mathrm{O}$ et al. (2016) bahwa wanita lebih mudah mengalami kecemasan dua kali lebih besar daripada pria. Studi ini juga menemukan bahwa orang Eropa Barat dan Amerika Utara lebih mudah menderita kecemasan daripada orang dari budaya yang berbeda. Secara terperinci dinyatakan bahwa prevalensi kecemasan secara umum adalah 3,8-25\%, wanita 5,2$8,7 \%$, dewasa muda 2,5-9,1\%; pasien dengan penyakit kronis $1,4-70 \%$; dan orang dari Euro/Anglo 3,8-10,4\% lebih tinggi dibanding dari Indonesia/Asia 2,8\%, Afrika 4,4\%, Eropa Tengah/Timur $3,2 \%$, Afrika Utara/Timur Tengah 4,9\%, dan Budaya Ibero/Latin 6,2\% (Remes et al., 2016).

Perbedaan yang lain pada jenis kelamin ini adalah disebabkan karena kemistri otak (brain chemistry), fluktuasi hormonal pada wanita berbeda dibandingkan pria. Wanita dengan adanya pengaruh hormonal lebih mudah mengalami perubahan pada perasaan, dan kurang mampu menjaga stabilitas emosinya.
Berdasarkan tabel 1 pada kelompok pendidikan menunjukkan bahwa hampir setengah responden tidak sekolah yaitu 13 responden (32\%), dan sebagian kecil responden pendidikan terakhir SMA dan PT ada 2 responden (5\%). Kecemasan yang dialami responden ditemukan pada responden yang tidak sekolah. Hubungan pendidikan dengan terjadinya kecemasan diafirmasi oleh penelitian Puspitasari (2013), dimana dinyatakan bahwa terdapat korelasi negatif yang cukup signifikan antara tingkat kecemasan dan tingkat pendidikan. Pendidikan subyek semakin tinggi, tingkat kecemasan semakin rendah dan tingkat pendidikan subyek yang rendah didapatkan tingkat kecemasan yang semakin tinggi (Puspitasari, 2013).

Berdasarkan tabel 1 bagian terjadinya kecemasan dan tingkat kecemasan dengan hasil sebagian besar responden tidak terjadi kecemasan sebanyak 23 responden $(56 \%)$ dan hampir setengah terjadi kecemasan sebanyak 18 responden (44\%) dan seluruhnya dengan tingkat kecemasan ringan. Sebagian besar lansia yang menjadi responden tidak mengalami kecemasan. Teori Kaplan dan Sadock (2010) mengemukakan bahwa individu berusia muda lebih mudah mengalami gangguan kecemasan dari pada individu yang lebih tua (Sadock dan Sadock, 2010). Kematangan pengalaman dalam menghadapi masalah-masalah kehidupan menjadikan lansia lebih tenang dan tidak mudah mengalami kecemasan. Awal lansia dimulai umur 60 tahun, kondisi yang membutuhkan adaptasi dari perubahan-perubahan fisik, psikologis, sosial dan kognitif.

Lansia yang mengalami kecemasan disebabkan oleh berbagai faktor. Kaplan dan Sadock (2010) dan Stuart (2013) mengatakan bahwa kecemasan dapat dipengaruhi oleh dua faktor yaitu faktor eksternal dan faktor internal. Faktor eksternal adalah adanya ancaman pada integritas fisik dan ancaman pada sistem 
diri dan faktor internal yaitu usia, stresor, jenis kelamin, lingkungan dan pendidikan (Sadock dan Sadock, 2010; Stuart, 2013). Teori Analitik dari Sigmund Freud mengatakan bahwa adanya konflik antara identitas dan superego dapat menyebabkan terjadinya kecemasan. Adapun pada penelitian ini kecemasan yang terjadi pada lansia seluruhnya dengan tingkat kecemasan ringan dan tidak satupun yang mengalami kecemasan sedang, berat dan panik.

Kecemasan atau kekhawatiran yang berlebihan adalah gejala yang diekspresikan. Penegakan diagnosis kecemasan apabila terdapat kekhawatiran berlebihan dengan adanya dua gejala atau lebih dan berlangsung selama 6 bulan atau lebih lama. Gejala kecemasan sesuai dengan DSM-IV-TR terdapat 18 gejala kecemasan, antara lain kegelisahan, mudah lelah, kesulitan konsentrasi, lekas marah, ketegangan otot dan gangguan tidur (Gorman dan Anwar, 2014).

Pencegahan terjadinya kecemasan pada lansia sangatnya penting untuk dilakukan. Pemberian informasi tentang proses menua dan penerimaan diri yang baik akan meminimalisir terjadinya kecemasan pada lansia.

\section{PENUTUP}

Kesimpulan

Gambaran kejadian dan tingkat kecemasan pada lanjut usia sebagian besar tidak terjadi kecemasan dan hampir setengahnya mengalami kecemasan dengan tingkat ringan.

Saran

Edukasi tentang perubahanperubahan lansia sangat penting diberikan kepada pra lansia, agar mempersiapkan diri dalam menghadapi masa lanjut usia.

\section{DAFTAR PUSTAKA}

American Psychological Association. (2019). Anxiety. Apa.Org. https:// www.apa.org/topics/anxiety/index
Azizah, L. M. (2011). Keperawatan Lanjut Usia (1st ed.). Graha Ilmu.

Constantinides, P. (1994). General Pathobiology (1 edition). Appleton \& Lange.

Gorman, L. M., \& Anwar, R. (2014). Neeb's Fundamentals of Mental Health Nursing, 4th Edition. F.A. Davis Company.

Gray, J. R., Grove, S. K., \& Sutherland, S. (2016). Burns and Grove's The Practice of Nursing Research: Appraisal, Synthesis, and Generation of Evidence (8 edition). Saunders.

Harvard Medical School. (2018). Anxiety and physical Illness: Understanding and treating anxiety can often improve the outcome of chronic disease, such as GI tract problems and heart disease. Harvard Health Publishing. https:// www.health.harvard.edu/stayinghealthy/anxiety_and_physical_illness

Kar, N. (2019). Holistic Care For Older Adults Needs Attention To Multimorbidity. Journal of Geriatric Care and Research, 6(1), 1-2.

Keliat, B. A. (2013). Community Mental Health Nursing (CMHN). Salemba.

Kementerian Kesehatan RI. (2014). InfoDATIN Pusat Data dan Informasi; Situasi dan Analisis Lanjut Usia. Kementerian Kesehatan RI, Pusat Data dan Informasi.

Maramis, W. F., \& Maramis, A. A. (2009). Catatan Ilmu Kedokteran Jiwa (edisi 2). Airlangga University Press.

Maryam, S. (2008). Mengenal Usia Lanjut dan Perawatannya. Salemba Medika.

Nursalam. (2014). Metodologi Penelitian Ilmu Keperawatan. Salemba Medika.

Polit, D. F., \& Hungler, B. P. (1999). Study Guide to Accompany Nursing Research: Principles and Methods (6th edition). Lippincott Williams \& Wilkins.

Profil Jatim. (2017). Profil Penduduk Lanjut Usia Provinsi Jawa Timur. Badan Pusat Statistik Jawa Timur.

Profil Kesehatan Indonesia. (2012). Situasi dan Analisis Lanjut Usia. Info Datin, Pusat Data dan Informasi Kementrian 
Kesehatan RI.

Puspitasari, A. W. T. (2013). Hubungan antara Tingkat Pendidikan dengan Kecemasan pada Wanita Menopause. Universitas Sebelas Maret.

Remes, O., Brayne, C., van der Linde, R., \& Lafortune, L. (2016). A systematic review of reviews on the prevalence of anxiety disorders in adult populations. Brain and Behavior, 6(7), e00497. https://doi.org/10.1002/ brb3.497

Sadock, B. J., \& Sadock, V. A. (2010). Buku Ajar Psikiatri Klinis Kaplan \& Sadock (Edisi 2). EGC.

Setiadi. (2013). Konsep dan Praktik Penulisan Riset Keperawatan (Edisi 2). Graha Ilmu.

Stuart, G. W. (2013). Buku Saku Keperawatan Jiwa (Edisi 5). EGC.

Sugiyono. (2006). Statistika untuk Penelitian. CV Alfabeta.
Videbeck, S. L. (2011). Psychiatric-Mental Health Nursing Fifth Edition (5th ed.). Lippincott Williams \& Wilki ns.

Welzel, F. D., Stein, J., Röhr, S., Fuchs, A., Pentzek, M., Mösch, E., Bickel, H., Weyerer, S., Werle, J., Wiese, B., Oey, A., Hajek, A., König, H. H., Heser, K., Keineidam, L., Van Den Bussche, H., Van Der Leeden, C., Maier, W., Scherer, M., ... Van Den Bussche, H. (2019). Prevalence of anxiety symptoms and their association with loss experience in a large cohort sample of the oldest-old. Results of the AGECODE/AGEQUALIDE study. Frontiers in Psychiatry, 10(MAY), 285. https://doi.org/10.3389/fpsyt. 2019.00285

World Health Organization. (2011). Global Health and Aging. National Institute on Aging National Institutes of Health NIH Publication. 